Journal of Agricultural Sciences
(Tarim Bilimleri Dergisi)

\title{
Natural Vanillin Production from Isoeugenol by Using Pseudomonas putida in Biphasic Bioconversion Medium
}

\author{
Huseyin KARAKAYA ${ }^{\mathrm{a}}$ (D), Murat YILMAZTEKIN ${ }^{\mathrm{a} *}$ (D)

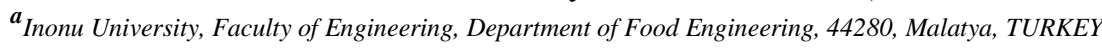 \\ ARTICLE INFO \\ Research Article \\ Corresponding Author: Murat YILMAZTEKIN, E-mail: murat.yilmaztekin@inonu.edu.tr \\ Received: 22 January 2021 / Revised: 8 May 2021 / Accepted: 14 July2021 / Online: 01 September 2022 \\ Cite this article \\ KARAKAYA H, YILMAZTEKIN M (2022). Natural Vanillin Production from Isoeugenol by Using Pseudomonas putida in Biphasic Bioconversion Medium. Journal of Agricultural \\ Sciences (Tarim Bilimleri Dergisi), 28(3):423-429. DOI: 10.15832/ankutbd.866426
}

\section{ABSTRACT}

Vanillin, is one of the most demanded flavoring agents in the world. Because of insufficient supply of natural vanillin, market demand is usually supplied by synthetic ones. In this study, it was investigated possibility of usage biphasic system in bioconversion of isoeugenol to vanillin by Pseudomonas putida (HUT 8100). Organic phase was composed of isoeugenol while biocatalyst, $P$. putida culture, was dispersed in aqueous phosphate solution. Isoeugenol was used as sole carbon source in concentrations ranging between $50-600 \mathrm{~g} \mathrm{~L}^{-1}$. Incubation was performed at $28{ }^{\circ} \mathrm{C}$, at $\mathrm{pH} 6.3$ and $180 \mathrm{rpm}$ shaking. Effect of initial substrate concentration and bioconversion time were investigated. Isoeugenol and vanillin amounts in medium were simultaneously analyzed in HPLC system. After $120 \mathrm{~h}$ incubation, vanillin reached the its highest level when $400 \mathrm{~g} \mathrm{~L}^{-1}$ isoeugenol was applied in medium. In specified conditions, it was achieved to produce $11.95 \mathrm{~g} \mathrm{~L}^{-1}$ vanillin with $6.2 \%$ molar yield within 15 days of bioconversion. It is thought that, obtained result by using biphasic system is very important for the industrial applications in production of natural vanillin via bioconversion.

Keywords: Bioconversion, Biphasic system, Isoeugenol, Natural flavor, Vanillin

\section{Introduction}

Vanillin (4-hydroxy-3-methoxybenzaldehyde) which naturally occurs in vanilla orchid pods, is one of the most important flavoring compounds (Singh et al. 2015). It is widely used in food, beverages, perfume and pharmaceutical industries (Zhao et al. 2018). However, vanillin derived from the pods serves less than 1\% of global market volume (Singh et al. 2015). 85\% of annual vanillin production is came from a petro-based compound, guaiacol, and the rest is synthesized from lignin (Zhu et al. 2018). Market value of synthetic vanillin is only about $10-20 \mathrm{USD} \mathrm{kg}^{-1}$ while vanillin derived from Vanilla spp. is 1500 USD $\mathrm{kg}^{-1}$ (van Leeuwen et al. 2018). Although there is a distinct price advantage of the synthetic counterparts, consumer interests to natural compounds, that considered as healthy, has forced many companies to discover new strategies to produce natural flavors such as vanillin (Luziatelli et al. 2019).

Biotechnological approaches have been known for many years and they include more environment-friendly processes compared to chemical synthesis (Franco et al. 2017). Compounds produced by biotechnological routes are labeled as "natural" according to Europe (EC 1334/2008, EC 1223/2009, EC 872/2012) and US (US CFR 1990) regulations (Castro et al. 2021). Isoeugenol has been raised concern of researchers being convertible to vanillin in one-step besides to be cheap and commercially available (Wang et al. 2021). Unfortunately, majority of aromatic compounds has cytotoxic activity on biocatalyst cells (Priebe \& Daugulis 2018). In recent years, biphasic system (organic/inorganic) has been preferred in bio-flavor studies to overcome this problem. In this method, a non-aqueous phase is used to sequester the substrate from aqueous solution that includes the cells. Low amount of substrate is continuously transferred between the phases from non-aqueous to aqueous (Priebe et al. 2018). It also provides a protection to the cells against product toxicity (Bicas et al. 2010). Using biphasic medium offers numerous advantages for biotransformation studies apart from prevention of toxicity. Dissolution of product in one of the phases ensures in situ removal and makes recovering process easier (Chreptowicz \& Mierzejewska 2018). Losses depend on volatility can be decreased in biphasic system, especially working with monoterpenic constituents. Bioconversion yield may be raised by manipulating oxygen transfer rate in medium according to organic phase features (Bicas et al. 2010). It was investigated usage of biphasic system in various flavor production studies such as cinnamyl alcohol (Zhang et al. 2020), 2-phenylethanol (Chreptowicz \& Mierzejewska 2018), R-(+)- $\alpha$-terpineol (Bicas et al. 2010) and concluded that the method was very effective on raising catalytic performance of the cells. Unlike the other vanillin studies, Zhao et al. (2005) used a biphasic medium containing $60 \%(\mathrm{v} / \mathrm{v})$ isoeugenol and achieved to produce $32.5 \mathrm{~g} \mathrm{~L}^{-1}$ vanillin which is the highest in literature, according to our knowledge. 
A strong growth is expected in natural vanillin market with a compound annual growth rate (CAGR) of $7.4 \%$ from 2017 to 2025. In natural vanillin production, biotechnological approaches give an opportunity for producers (Luziatelli et al. 2019). Unfortunately, the production amounts remain very low due to substrate toxicity and hence, basic dispersion method is not applicable for industrial production. Thus, it is put emphasis on developing of current processes or constructing new alternative routes (Franco et al. 2017). Biphasic system has been come to the fore with high production rates as mentioned above. There is limited number of works for vanillin production in organic/inorganic bioconversion medium. Effects of temperature, $\mathrm{pH}$ and aeration in aqueous bioconversion medium were reported in our previous study (Karakaya \& Y1lmaztekin 2020). However, it was not possible to give results of biphasic (organic/inorganic) system within the same article due to limited scope. In this study, it was aimed to investigate biphasic medium usage for increasing vanillin production.

\section{Material and Methods}

\subsection{Microorganism culture and chemicals}

P. putida (HUT 8100) strain was supplied from HUT Culture Collection (Hiroshima, Japan). Culture was stored in IFO 802 (Institute of Fermentation, Osaka, Japan) medium slants at $+4{ }^{\circ} \mathrm{C}$ until use. IFO 802 medium was prepared according to instructions of culture collection as followings: $10 \mathrm{~g} \mathrm{~L}^{-1}$ peptone, $2 \mathrm{~g} \mathrm{~L}^{-1}$ yeast extract, $1 \mathrm{~g} \mathrm{~L}^{-1} \mathrm{MgSO}_{4}$ and $15 \mathrm{~g} \mathrm{~L}^{-1}$ agar (HUT 2015).

Ethanol (96\%, food grade) was purchased from Tekkim (Bursa, Turkey). Acetic acid (chromatographic grade) was supplied from Carlo-Erba (Milano, Italy). Medium ingredients, methanol, vanillin, isoeugenol and all other chemicals were purchased from Sigma-Aldrich (St. Louis, MO) unless otherwise specified.

\subsection{Preparation of resting cells and bioconversion medium}

Microorganism culture was grown in Glucose-Yeast Extract-Peptone (GYP) broth before inoculating to bioconversion medium. GYP was prepared in $1 \mathrm{~L}$ distilled water as followings: $5 \mathrm{~g}$ glucose, $5 \mathrm{~g}$ yeast extract, $5 \mathrm{~g}$ peptone, $14 \mathrm{~g} \mathrm{~K}_{2} \mathrm{HPO}_{4} .3 \mathrm{H}_{2} \mathrm{O}, 5.2 \mathrm{~g}$ $\mathrm{KH}_{2} \mathrm{PO}_{4}$ and $1 \mathrm{~g} \mathrm{MgSO}_{4} .7 \mathrm{H}_{2} \mathrm{O}$ (Zhao et al. 2005). $250 \mathrm{~mL}$-sterile flasks containing $50 \mathrm{~mL}$ of GYP broth were inoculated with a loopful bacterial culture. They were incubated at $28^{\circ} \mathrm{C}$ and $180 \mathrm{rpm}$ orbital shaking (Sartorius Certomat IS, Germany) for $48 \mathrm{~h}$. Medium contents were divided to two equal portions of $25 \mathrm{~mL}$ and transferred into sterile $50 \mathrm{~mL}$-polypropylene tubes at the end of incubation. The tubes were centrifugated with $3600 \mathrm{xg}$ at $4{ }^{\circ} \mathrm{C}$ for $15 \mathrm{~min}$ (Thermo Scientific SL 16R, MA). Clarified liquid sections were discarded and biomass in each tube was reconstituted with appropriate amount of phosphate buffer solution (4.84 $\mathrm{g} \mathrm{L}^{-1} \mathrm{~K}_{2} \mathrm{HPO}_{4}$ and $16.65 \mathrm{~g} \mathrm{~L}^{-1} \mathrm{KH}_{2} \mathrm{PO}_{4}, \mathrm{pH}$ : 6.3). Suspensions were homogenized and combined in a $250 \mathrm{~mL}$-flask to obtain resting cells (Karakaya \& Y1lmaztekin 2020).

A total of $20 \mathrm{~mL}$ bioconversion medium was used in biphasic system trials. The aqueous part was formed by phosphate solution with resting cells while the organic phase was solely consisted of isoeugenol. The amount of substrate must be sufficient to form two distinctly separated surfaces. For the purpose, initial isoeugenol concentration was used in range of 50-600 $\mathrm{g} \mathrm{L} \mathrm{L}^{-1}$. Higher concentrations were not applied, since the aqueous phase was not capable of covering organic surface, completely. Bioconversion medium was left to incubation at $28{ }^{\circ} \mathrm{C}$ and $180 \mathrm{rpm}$ orbital shaking for $120 \mathrm{~h}$. Initial substrate ratio which provides maximal vanillin production was applied in bioconversion time trials. A separate flask was prepared with same content for each sampling time. At the end of target sampling time, whole flask content was extracted according to the procedures given in Section 2.4. Unused isoeugenol and produced vanillin amounts were determined by HPLC system. Time trials were continued until no significant change was observed in vanillin accumulation between successive samplings.

\subsection{Viability test}

Cell viability was checked with $p$-iodo nitrotetrazolium (INT) indicator. Samples $(2 \mathrm{~mL})$ were collected from bioconversion medium into sterile test tubes and $0.4 \mathrm{~mL}$ INT solution $\left(0.2 \mathrm{mg} \mathrm{mL}^{-1}\right.$, in distilled water) was dropped into each tube. Procedure was applied the sample tubes which contains uninoculated bioconversion medium, too. Tubes were incubated for additional 30 min at $28{ }^{\circ} \mathrm{C}$ without shaking. Viability was determined according to red color formation in the tubes (Eloff 1998).

\subsection{Extraction}

Extraction was performed following after incubation in concentration (120 h) and time (1-17 days) trials. The bioconversion medium $(20 \mathrm{~mL})$ was transferred to 50 - $\mathrm{mL}$ polypropylene tubes in given sampling time. $96 \%$ ethanol was added over in ratio of 1:1 (v:v) and the tubes were homogenized for $1 \mathrm{~min}$. Suspension was centrifugated with $3600 \mathrm{xg}$ at $4{ }^{\circ} \mathrm{C}$ for $15 \mathrm{~min}$. Supernatant was taken to a new tube and $7.5 \mathrm{~mL}$ of $96 \%$ ethanol was added over biomass. The tube content was homogenized and centrifugated again in same conditions. The procedure was applied two times and supernatants were combined in a new tube. Extracts were filtered through $0.45 \mu \mathrm{m}$ nylon membrane filters and taken to amber colored HPLC vials ( $2 \mathrm{~mL})$ for analysis (Karakaya \& Y1lmaztekin 2020). 


\subsection{HPLC analysis}

Isoeugenol and vanillin amounts in bioconversion medium were determined by HPLC (Shimadzu LC-20A, Japan). Degasser (DGU-20A5), pump (LC-20AD), autosampler (SIL-20A) units and UV-visible detector (SPD-M20A) which are directly integrated to HPLC system were used for the purpose. Compound separation was achieved by Licrospher RP18 (25 cm x 4.60 $\mathrm{mm}, 5.5 \mu \mathrm{m}$ particle size) column. A binary solvent system was used as follows: ultrapure water containing $0.01 \%$ acetic acid (A) and methanol (99.9\%) (B). Gradient elution was applied according to procedures stated by Li et al. (2004), with minor modifications. Briefly, phase B was flowed as following ratios: $60 \%$ between 0-3 min, decrease to 50\% between 3-5 min, raise to $100 \%$ between $5-9 \mathrm{~min}$ and left to flow $100 \% \mathrm{~B}$ for $4 \mathrm{~min}$. It was decreased to $60 \%$ again between $13-15 \mathrm{~min}$ and flowed $60 \%$ mobile phase B for $3 \mathrm{~min}$ to prepare the column to next injection. Total analysis time was estimated 18 min. Elution was simultaneously screened with UV detector at $270 \mathrm{~nm}$. Isoeugenol and vanillin were identified by using authentic standards. Quantification was performed using a calibration curve prepared by five-point serial dilutions of corresponding standards. Bioconversion efficiency was determined with molar yield equation (1) (Karakaya \& Y1lmaztekin 2020):

Molar yield $(\%)=\frac{\text { Produced vanillin }(\mathrm{g}) \times \text { Molar weight of isoegenol }(\mathrm{g} / \mathrm{mol})}{\text { Consumed isoeugenol }(\mathrm{g}) \times \text { Molar weight of vanillin }(\mathrm{g} / \mathrm{mol})} \times 100$

\subsection{Statistical analysis}

Isoeugenol consumption and vanillin production in biphasic medium were analyzed by analysis of variance (ANOVA). Statistical analysis was carried out in SPSS package program version 16.0 (SPSS Inc., Chicago, IL). Tukey's multiple comparison test was used to compare means at a significance level of $\mathrm{P}<0.05$. All trials were performed in triplicate and results were expressed as mean \pm standard deviation.

\section{Results and Discussion}

\subsection{Cell viability}

Growing cells need energy to multiply their biomass and this causes a fall in bioconversion yield. Unlike growing cells, resting forms that non-growing but metabolically active, use their metabolism more efficiently due to high substrate specify (Julsing et al. 2012). It can be prepared by transferring of growing cells to phosphate buffer solutions (Hua et al. 2007; Yamada et al. 2007). In this study, culture was dispersed in $\mathrm{K}_{2} \mathrm{HPO}_{4}$ and $\mathrm{KH}_{2} \mathrm{PO}_{4}$ solution to obtain resting cells.

Biocatalyst were obliged to use limited isoeugenol dissolved in aqueous phase to survive. Cell death may occur in bioconversion medium depend on nutritional deficiency, substrate, product or by-product toxicity. If there is bacterial viability, color in test tubes turns to red in presence of INT indicator. There is no color change on the contrary (Eloff 1998). In both of initial concentration and bioconversion time trials, red color formation was observed in all test tubes which was accepted as evidence of bacterial viability. Bioconversion medium was found suitable to keep cells alive although it contained less ingredient compared to a simple growing medium. In addition, there was not encountered vanillin formation in the absence of either isoeugenol or cell culture in medium. Biphasic system results on viability were in accordance with previous findings (Karakaya \& Yilmaztekin 2020).

\subsection{Effect of initial substrate concentration}

It is known that many substrates and products in bioconversion studies have low solubility in water (Carreno et al. 2014). Isoeugenol may be thought unfavorable substrate for bioconversion because its solubility is only $6 \mathrm{mM}$ which is quite low (Yamada et al. 2007; Ashengroph et al. 2011). Actually, it presents an opportunity to use it in high concentration to form a biphasic system. Bioconversion media was prepared by using $50-600 \mathrm{~g} \mathrm{~L}^{-1}$ isoeugenol and left to incubation for $120 \mathrm{~h}$. The media containing 300 and $400 \mathrm{~g} \mathrm{~L}^{-1}$ isoeugenol were differed from the others with regard to significantly higher $(\mathrm{P}<0.05)$ vanillin content (Figure 1). It was produced $9.14 \pm 0.62 \mathrm{~g} \mathrm{~L}^{-1}$ vanillin in the medium containing $400 \mathrm{~g} \mathrm{~L}^{-1}$ isoeugenol. 


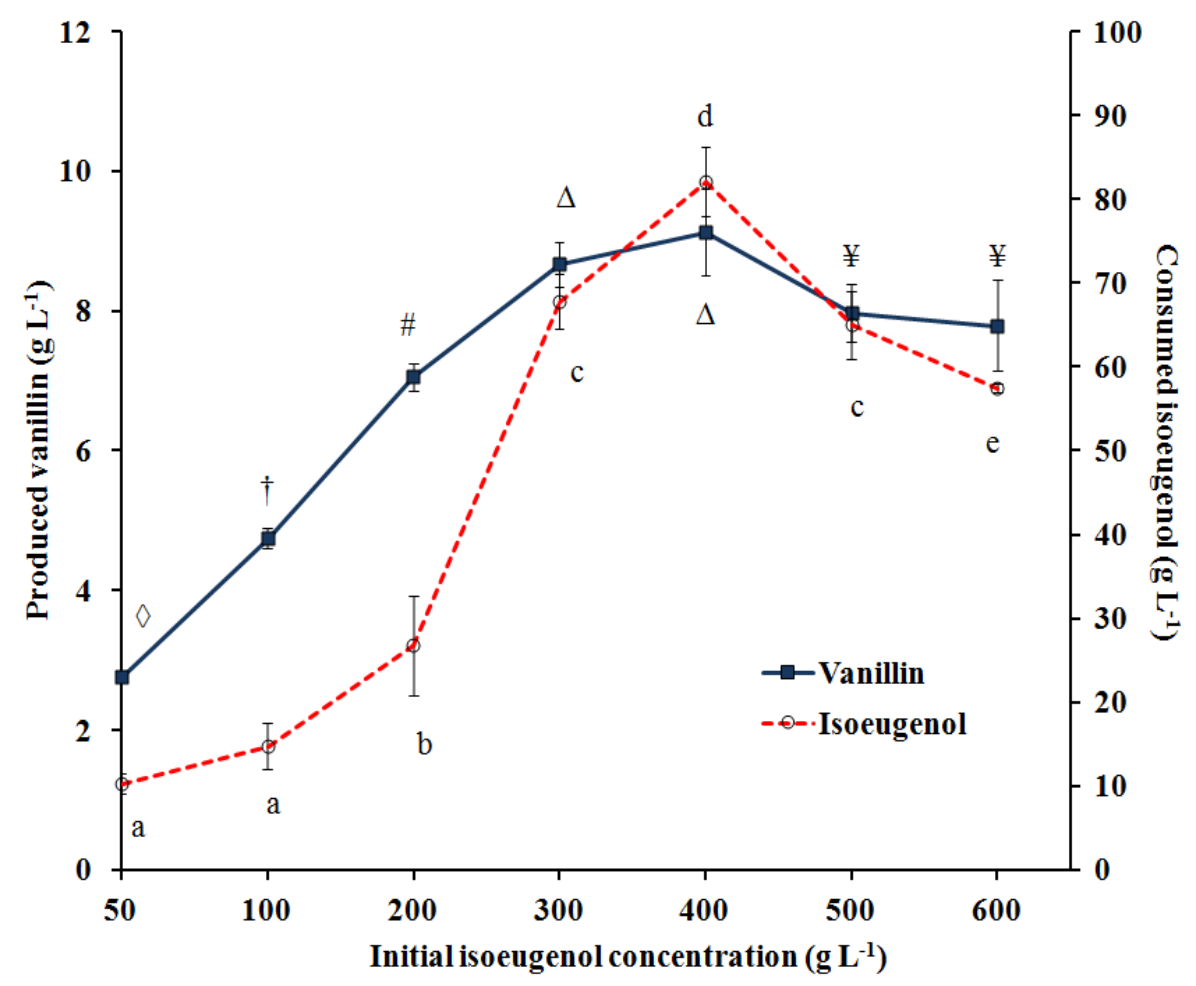

Figure 1- Changes in vanillin and isoeugenol amounts depending on different initial substrate concentrations (Error bars indicate standard deviation. Significant differences are marked with symbols for vanillin and letters for isoeugenol, $P<0.05$ )

Various biocatalysts were used in conversion of isoeugenol to vanillin, especially Arthrobacter (Shimoni et al. 2003), Bacillus (Hua et al. 2007), Trichosporon asahii (Ashengroph \& Amini 2017) and Pseudomonas (Yamada et al. 2007; Karakaya \& Y1lmaztekin 2020) species. Nevertheless, produced vanillin was less than $5 \mathrm{~g} \mathrm{~L}^{-1}$ in many of these studies. It was due to low solubility of isoeugenol, substrate or product toxicity on culture in aqueous dispersions (Ashengroph \& Amini 2017). In previous study, vanillin production in isoeugenol-phosphate dispersion was only about $877.9 \mathrm{mg} \mathrm{L}^{-1}$, although some conditions (pH, temperature and aeration) were optimized (Karakaya \& Y1lmaztekin 2020). In dispersion systems, access to substrate by cells may have been limited due to insufficient surface area depend on low isoeugenol concentration. Isoeugenol in high quantities acts as a substrate and solvent which cause an increase on vanillin production (Zhao et al. 2005). It is thought that biphasic system made easier to reach sole carbon source, isoeugenol, by $P$. putida cells. It allowed to use high substrate amounts up to $400 \mathrm{~g} \mathrm{~L}^{-1}$ without showing any toxic effect on biocatalyst. However, a decline in vanillin production was observed when higher substrate concentrations were applied. Biocatalytic activity is inhibited when substrate or product concentration exceeds the critical level (Carreno et al. 2014). Cell viability is an essential factor in whole cell biotransformation processes (Sendovski et al. 2010). It has been thought that dispersed isoeugenol ratio was increased enough to have toxic effect on the cells by using 500 $\mathrm{g} \mathrm{L}^{-1}$ isoeugenol or more.

P. putida cells performed an effective vanillin production yield although the medium was solely consisted of isoeugenol as carbon source. Bacterial contamination risk can be reduced due to nutrient deficient medium (Wang et al. 2006). Moreover, using minimal ingredients in medium makes the purification step easier in bioprocesses. Distinct differences between organic/inorganic phase features provide an efficient extraction of biomolecules (Nouri et al. 2019). On the other hand, separated layers in the medium effect oxygen transfer rate. Bicas et al. (2010) used sunflower oil as organic phase on top layer and decreased oxygen transfer rate to inorganic phase. Anaerobic condition was promoted R-(+)- $\alpha$-terpineol production in given study. However, lowering the oxygenation of medium adversely affects $P$. putida cells in vanillin bioconversion (Karakaya \& Y1lmaztekin 2020). In contrast to many essential oil constituents, density of isoeugenol is higher than water in constant temperature (Nielsen et al. 2017). Therefore, it showed tendency to precipitate in aqueous solutions and inorganic phase took part in upper side of biphasic system. It must have been facilitated the access to oxygen by cells.

\subsection{Bioconversion time}

Various parameters such as high production rates, yield and process duration have importance for industrial operations. Bioconversion was followed for 17 days in $400 \mathrm{~g} \mathrm{~L}^{-1}$ isoeugenol containing medium (Figure 2). It was determined a significant difference $(\mathrm{P}<0.05)$ on vanillin accumulation between beginning and ending days of bioconversion. Although there was a slight decrease in vanillin amount on 17th day, change was no meaningful. Aldehyde structured compounds have high chemical reactivity and in general, they rarely accumulate in biological systems (Muheim \& Lerch 1999). As an aldehyde, vanillin was expressed as an obligate intermediate for some Pseudomonas sp. (Overhage et al. 1999). It can be oxidized to vanillic acid or 
reduced to vanillyl alcohol depend on enzyme diversity of biocatalyst (Luziatelli et al. 2019). This fall may be due to further degradation of vanillin by biocatalyst to avoid product toxicity in harsh conditions. It was achieved to produce $11.95 \mathrm{~g} \mathrm{~L}^{-1} \mathrm{vanillin}$ with $6.2 \%$ molar yield after 15 days of bioconversion. $48.3 \%(\mathrm{w} / \mathrm{w})$ of isoeugenol remained unused at the moment. In past studies, it was stated that residual isoeugenol could be recovered and utilized once again in a new bioconversion cycle (Zhao et al. 2006).

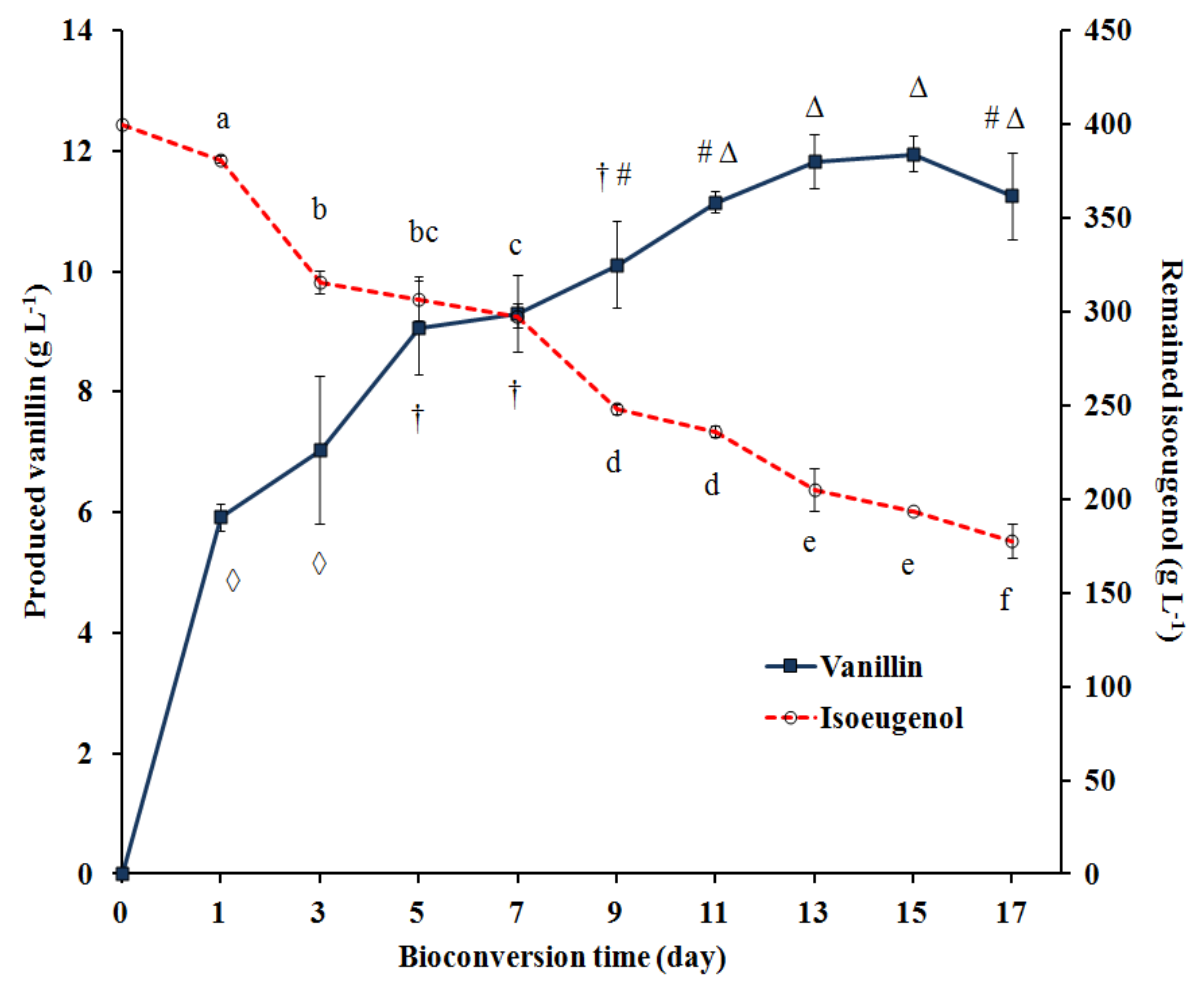

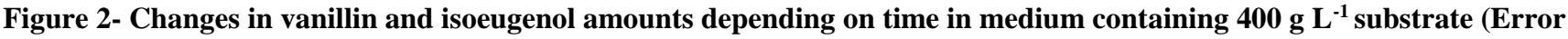
bars indicate standard deviation. Significant differences are marked with symbols for vanillin and letters for isoeugenol, $\mathbf{P}<\mathbf{0 . 0 5 )}$

It has been shown that multiple-feeding at different times promotes the vanillin production compared to single feeding strategy (Valerio et al. 2021). However, processes must be interrupted to replace the current medium with fresh one. Considering industrial mass production, it may lead to loss of time and contamination risk. As opposed to aqueous dispersions, feeding occurs spontaneously in biphasic system by transfer of limited amount of isoeugenol from organic to aqueous layer. Zhao et al. (2005) stated that $0.2-0.9 \mathrm{~g} \mathrm{~L}^{-1}$ isoeugenol was dispersed in aqueous phase when $60 \%$ isoeugenol and 180 rpm shaking were applied in biphasic medium. There are limited number of works came up with high vanillin yield but the techniques used in these studies had some disadvantageous properties. For instance, Yamada et al. (2007) achieved to produce $16.1 \mathrm{~g} \mathrm{~L}^{-1}$ vanillin with the help of $10 \%(\mathrm{v} / \mathrm{v})$ DMSO in bioconversion medium. Despite the fact that an effective vanillin production was carried out, method is unfeasible for industrial operations. DMSO presents high polarity and high boiling points and these make the product isolation impossible for further process steps. (Ashengroph \& Amini 2017). Since it was not desired to obtain uniform solution in this study, emulsifier agent was not used in medium. In another study, it was managed to produce $28.3 \mathrm{~g} \mathrm{~L}^{-1}$ vanillin by using recombinant E. coli cells (Yamada et al. 2008). However, genetic modified organisms have a negative effect on consumer perception and moreover they are perceived as risky, avoidable and fearful (Boccia et al. 2018). Biphasic system is taken attention because of its high production rates in various bioconversion process (Zhao et al. 2005; Chreptowicz \& Mierzejewska 2018; Zhang et al. 2020). It was aimed to enhance vanillin production by using biphasic medium in the study and findings are compatible with those of mentioned references.

\section{Conclusions}

In this study, natural vanillin was produced from isoeugenol as an alternative to botanical extracts. This work has been differed from past studies that was possible to apply high substrate concentrations in biphasic system avoiding substrate toxicity. Biocatalyst, $P$. putida (HUT 8100) culture, was dispersed in inorganic buffer solution and isoeugenol was used with the aim of both, substrate and organic phase. Distinct specifications of the phases (such as density and polarity) made easier to form a biphasic medium. Biocatalyst cells were in contact with substrate at the phase interface and not directly exposed to high amount of isoeugenol which provided a protection against to substrate toxicity. A limited amount of isoeugenol was continuously dispersed in aqueous phase by shaking. Thus, there was no need to substrate addition during bioconversion and spontaneous feeding was provided by organic layer. Using $400 \mathrm{~g} \mathrm{~L}^{-1}$ isoeugenol, it was achieved to produce $11.95 \mathrm{~g} \mathrm{~L}^{-1}$ vanillin with $6.2 \%$ 
molar yield in 15 days. Biphasic system has brought out higher vanillin production rate compared to many other reports on literature. It did not require to use of any emulsifier agent or additional nutrient. Therefore, it is expected to reduce operational costs and make the purification step easier due to minimal content. However, being free from toxic solvents makes the process eco-friendly and removes the risk of residual solvent in final product. It has been thought that findings have an importance for industrial scale production of bio-vanillin. It is suggested to work on residual isoeugenol utilization and vanillin purification for further studies. Using appropriate macroporous resin can provide an effective separation for both, isoeugenol and vanillin.

\section{Acknowledgements}

This study was supported by Inonu University Scientific Research Projects Coordination Unit (Project number: 2015/17). Authors owe to thanks to HUT Culture Collection in supply of bacteria culture.

\section{References}

Ashengroph M \& Amini J (2017). Bioconversion of isoeugenol to vanillin and vanillic acid using the resting cells of Trichosporon asahii. 3 Biotech 7: 358

Ashengroph M, Nahvi I, Zarkesh-Esfahani H \& Momenbeik F (2011). Use of growing cells of Pseudomonas aeruginosa for synthesis of the natural vanillin via conversion of isoeugenol. Iranian Journal of Pharmaceutical Research 10(4): 749-757

Bicas J L, Fontanille P, Pastore G M \& Larroche C (2010). A bioprocess for the production of high concentrations of R-(+)-aterpineol from R-(+)-limonene. Process Biochemistry 45: 481-486

Boccia F, Covino D \& Sarnacchiaro P (2018). Genetically modified foods versus knowledge and fear: A numeric approach for consumer behavior. Food Research International 111: 682-688

Carreno D M P, Quinones O M R, Calvo J R V \& Ochoa S H (2014). Bioconversion of (+)-nootkatone by Botryodiplodia theobromae using a membrane aerated biofilm reactor. Revista Mexicana de Ingenieria Quimica 13(3): 757-764

Castro P S, Soares F \& Santos P M (2021). Current advances in the bacterial toolbox for the biotechnological production of monoterpene-based aroma compounds. Molecules 26(91): 1-31

Chreptowicz K \& Mierzejewska J (2018). Enhanced bioproduction of 2-phenylethanol in a biphasic system with rapeseed oil. New Biotechnology 42: 56-61

Eloff J N (1998). A sensitive and quick microplate method to determine the minimal inhibitory concentration of plant extracts for bacteria. Planta Medica 64: 711-713

Franco A, De S, Balu A M, Romero A A \& Luque R (2017). Selective oxidation of isoeugenol to vanillin over mechanochemically synthesized aluminosilicate supported transition metal catalysts. ChemistrySelect 2: 9546-9551

Hua D, Ma C, Lin S, Song L, Deng Z, Maomy Z, Zhang Z, Yu B \& Xu P (2007). Biotransformation of isoeugenol to vanillin by a newly isolated Bacillus pumilus strain: identification of major metabolites. Journal of Biotechnology 130: 463-470

HUT (2015). Medeum. Retrieved in June, 11, 2015 from https://home.hiroshima-u.ac.jp/hut/mideum.html

Julsing M K, Kuhn D, Schmid A \& Bühler B (2012). Resting cells of recombinant E. coli show high epoxidation yields on energy source and high sensitivity to product inhibition. Biotechnology and Bioengineering 109(5): 1109-1119

Karakaya H \& Yılmaztekin M (2020). Pseudomonas putida ile izoöjenolden doğal vanilin üretiminde bazı ortam koşullarının molar verim üzerine etkisi. Glda 45(1): 9-19

Li Y H, Sun Z H \& Zheng P (2004). Determination of vanillin, eugenol and isoeugenol by RP-HPLC. Chromatographia 60: 709-713

Luziatelli F, Brunetti L, Ficca A G \& Ruzzi M (2019). Maximizing the efficiency of vanillin production by biocatalyst enhancement and process optimization. Frontiers in Bioengineering and Biotechnology 7: 279

Muheim A \& Lerch K (1999). Towards a high-yield bioconversion of ferulic acid to vanillin. Applied Microbiology and Biotechnology 51: 456-461

Nielsen C K, Kjems J, Mygind T, Snabe T, Schwarz K, Serfert Y \& Meyer R L (2017). Antimicrobial effect of emulsionencapsulated isoeugenol against biofilms of food pathogens and spoiled bacteria. International Journal of Food Microbiology 242: 7-12

Nouri M, Shahriari S \& Pazuki G (2019). Increase of vanillin partitioning using aqueous two phase system with promising nanoparticles. Scientific Reports 9: 19665

Overhage J, Priefert H, Rabenhorst J \& Steinbüchel A (1999). Biotransformation of eugenol to vanillin by a mutant of Pseudomonas sp. strain HR199 constructed by disruption of the vanillin dehydrogenase (vdh) gene. Applied Microbiology and Biotechnology 52: 820-828

Priebe X \& Daugulis A J (2018). Thermodynamic affinity-based considerations for the rational selection of biphasic systems for microbial flavor and fragrance production. Journal of Chemical Technology \& Biotechnology 93: 656-666

Priebe X, Daschner M, Schwab W \& Weuster-Botz D (2018). Rational selection of biphasic reaction systems for geranyl glucoside production by Escherichia coli whole-cell biocatalysts. Enzyme and Microbial Technology 112: 79-87

Sendovski M, Nir N \& Fishman A (2010). Bioproduction of 2-phenylethanol in a biphasic ionic liquid aqueous system. Journal of Agricultural and Food Chemistry 58: 2260-2265

Shimoni E, Baasov T, Ravid U \& Shoham Y (2003). Biotransformations of propenylbenzenes by an Arthrobacter sp. and its $t$ anethole blocked mutants. Journal of Biotechnology 105: 61-70 
Singh B, Khan S, Pandey S S, Singh M, Banerjee S, Kitamura Y \& ur Rahman L (2015). Vanillin production in metabolically engineered Beta vulgaris hairy roots through heterologous expression of Pseudomonas fluorescens HCHL gene. Industrial Crops and Products 74: 839-848

Valerio R, Bernardino A R S, Torres C A V, Brazinha C, Tavares M L, Crespo J G \& Reis M A M (2021). Feeding strategies to optimize vanillin production by Amycolatopsis sp. ATCC 39116. Bioprocess and Biosystems Engineering 44: 737-747

van Leeuwen K A, Prenzler P D, Ryan D, Paolini M \& Camin F (2018). Differentiation of wood-derived vanillin from synthetic vanillin in distillates using gas chromatography/combustion/isotope ratio mass spectrometry for $\delta^{13} \mathrm{C}$ analysis. Rapid Communication in Mass Spectrometry 32: 311-318

Wang Z, Zhao F, Chen D \& Li D (2006). Biotransformation of phytosterol to produce androsta-diene-dione by resting cells of Mycobacterium in cloud point system. Process Biochemistry 41: 557-561

Wang Q, Wu X, Lu X, He Y, Ma B \& Xu Y (2021). Efficient biosynthesis of vanillin from isoeugenol by recombinant isoeugenol monooxygenase from Pseudomonas nitroreducens Jin1. Applied Biochemistry and Biotechnology, Published online: 07.01.2021

Yamada M, Okada Y, Yoshida T \& Nagasawa T (2007). Biotransformation of isoeugenol to vanillin by Pseudomonas putida IE27 cells. Applied Microbiology and Biotechnology 73: 1025-1030

Yamada M, Okada Y, Yoshida T \& Nagasawa T (2008). Vanillin production using Escherichia coli cells over-expressing isoeugenol monooxygenase of Pseudomonas putida. Biotechnology Letters 30: 665-670

Zhang C, Xu Q, Hou H, Wu J, Zheng Z \& Ouyang J (2020). Efficient biosynthesis of cinnamyl alcohol by engineered Escherichia coli overexpressing carboxylic acid reductase in a biphasic system. Microbial Cell Factories 19: 163

Zhao L Q, Sun Z H, Zheng P \& Zhu L L (2005). Biotransformation of isoeugenol to vanillin by a novel strain of Bacillus fusiformis. Biotechnology Letters 27: 1505-1509

Zhao L Q, Sun Z H, Zheng P \& He J Y (2006). Biotransformation of isoeugenol to vanillin by Bacillus fusiformis CGMCC1347 with the addition of resin HD-8. Process Biochemistry 41: 1673-1676

Zhao L, Xie Y, Chen L, Xuefeng X, Zhao C X \& Cheng F (2018). Efficient biotransformation of isoeugenol to vanillin in recombinant strains of Escherichia coli by using engineered isoeugenol monooxygenase and sol-gel chitosan membrane. Process Biochemistry 71: 76-81

Zhu Y, Liu J, Liao Y, Lv W, Ma L \& Wang C (2018). Degradation of vanillin during lignin valorization under alkaline oxidation. Topics in Current Chemistry 376: 29

(C) 2022 by the author(s). Published by Ankara University, Faculty of Agriculture, Ankara, Turkey. This is an Open Access article distributed under the terms and conditions of the Creative Commons Attribution (CC BY) license (http://creativecommons.org/licenses/by/4.0/), which permits unrestricted use, distribution, and reproduction in any medium, provided the original work is properly cited. 